\title{
Orthorectification and Digital Elevation Model (DEM) Generation Using Cartosat-1 Satellite Stereo Pair in Himalayan Terrain
}

\author{
Vivek Kumar Singh ${ }^{1}$, Prashant Kumar Champati Ray ${ }^{2}$, Ayyeum Perumal Thillai Jeyaseelan ${ }^{1}$ \\ ${ }^{1}$ Jharkhand Space Applications Center, Department of Information Technology, \\ Government of Jharkhand, Ranch, India \\ ${ }^{2}$ Indian Institute of Remote Sensing (IIRS), Department of Space, Government of India, \\ Dehradun, Uttarakhand, India \\ E-mail:vivekearth@gmail.com
}

\begin{abstract}
High resolution data have high relief displacement in hilly terrains. Development of Digital Elevation model helps to assess bio resources more accurately in such terrains. While estimating bio resources in the Himalayan hilly terrain using multispectral LISS-III data of $23 \mathrm{~m}$ spatial resolution, the need for orthorectifcation of satellite data was necessary to correct for spatial distances due to high undulating slopes. Therefore, Cartosat stereo pair based Digital Elevation Model (DEM) was generated using the Rational Polynomial Coefficients (RPC) supplied along with the data products. By using the DEM orthorectification of LISS-III was created. In order to evaluate the positional accuracy of ortho rectified LISS-III Ground control points were selected using the Global Positioning System in differential GPS mode. As there is variation in the spatial distances and height over few points, the GCP corrected DEM was used for ortho rectifcation of Cartosat PAN and LISS-III data. This paper presents the procedure followed for ortho rectification and digital elevation model generation using Cartosat stereo pair data. The result of the study indicated high spatial resolution stereo images helped generation of three dimensional mountainous regions more accurately which helps in estimating the bio resources using multispectral LISS III data.
\end{abstract}

Keywords: DEM, Cartosat, Stereo Pair, Orthorectification, Himalaya

\section{Introduction}

Stereo imaging from space-borne platforms offers information about terrain elevation besides supplying spectral reflectance of the scene. This greatly assists the analysis and interpretation of images in terms of identifying slopes, surface material, waterways, vegetation growth etc. Applications like urban planning, agriculture, defence etc., need to use Digital Elevation Model (DEM) derived from stereo images, which is an important component of geo-spatial data. With the launch of Cartosat-1, ISRO's first satellite with along track stereo capability in May 2005 by PSLV-C6 vehicle, a new possibility has emerged for remote sensing and Mapping communities. The high-resolution stereo data beamed from twin cameras onboard Cartosat-1 mission facilitates topographic mapping up to $1: 25,000$ scale [1]. The primary advantage of Cartosat-1 mission is seen as generation of Digital
Elevation Model (DEM) for production of Orthoimage and 3D terrain visualization of large tracts of landmass at fairly large scale. The 10 bits per pixel radiometric resolution of Cartosat-1 sensors allows for improved discrimination of objects, which enhances the cartographic potential of the sensor. The satellite has shown a very stable attitude behavior, which in turn helps in realizing data products with low internal distortion.

Cartosat- 1 is the first operational remote sensing satellite capable of providing in-orbit stereo images with $2.5 \mathrm{~m}$ nadir resolution and $27 \mathrm{~km}$ swath. The two payloads viz. PAN-Fore and PAN-Aft are designed with state-ofthe-art technologies in order to provide images of high quality $[1,2]$. They are mounted in along track direction with fixed tilts of +26 deg (Fore) and -5 deg (Aft) respecttively to provide along track stereo, each with approximately $2.5 \mathrm{~m}$ ground resolutions.

Satellite Photogrammetry techniques have been extensively used by the scientific community in deriving high 
resolution DEM, Ortho image and terrain parameters such as slope, aspect, contours, drainage etc. Digital Elevation Model (DEM) has become an inevitable component in most of the remote sensing applications viz. infrastructure development, watershed management and development, hydro-geomorphology, urban morphology, disaster management etc. Keeping these applications in view, the current study aimed at exploitation of Cartosat-1 stereo data for various applications.

Rational functions models (RFMs) have gained popularity, with the recent advent of high resolution data supplying Rational Polynomial Coefficients (RPCs) along with stereo/mono data. Providing these coefficients along with stereo data, instead of delivering the interior and exterior orientation parameters and other properties related to physical Sensor, one can proceed to satellite photogram metric processes which approximate the sensor model itself. A detailed study of the RFMs for photogrammetric processing has been carried out by Tao and $\mathrm{Hu}$ [3]. Di [4] demonstrated different ways to improve the geo-positioning accuracy of Ikonos stereo imagery by either refining the vendor provided RF (Rational Function) coefficients, or refining the RF derived ground coordinates. Poon [5] focuses on Digital Surface Model (DSM) generation from high resolution satellite imagery (HRSI) using different commercial of the shelf (COTS) packages. They validated the stereo DEM with InSAR DEM for different land forms. Nadeem [6] validated DEM generated from Cartosat-1 stereo data.

Crespi [7] evaluated the DSM by comparing the heights of several buildings and points on the road axis derived from a large scale $(1: 2000)$ 3D map. Fracer and Hanley [8] demonstrated the wide applicability of bias compensated RPCs for high accuracy geo-positioning from stereo HRSI for a mountainous terrain. Chen [9] compared geometrical performance between rigorous sensor model (RSM) and RFM in the sensor modeling of FORMOSAT-2 satellite image. Dabrowski [10] evaluated DEMs generated with different numbers of GCPs from Cartosat-1 stereo data at large number of evenly distributed check points. Similar attempts to evaluate the accuracy of the DEM using different number of GCPs have been made by Michalis and Dowman [11] and Rao [12].

\section{Study Area}

The study area in Chamoli district lies in the northeastern part of Uttarakhand state (Figure 1). It is bounded by North Latitude 29 $55^{\prime} 00^{\prime \prime} \& 31^{\circ} 03^{\prime} 45^{\prime \prime}$ and East Longitude $79^{\circ} 02$ ' $39^{\prime \prime}$ \& 80 $80^{\circ}$ '29” and falls in Survey of India toposheet nos. $53 \mathrm{O}, \mathrm{M}$ and $\mathrm{N}$. The geographical area of the district is $7820 \mathrm{~km}^{2}$. Chamoli district the sec- ond largest district of Uttarakhand, is also important from strategic point of view as it shares its northern boundary with Tibet (China). Geologically the area be- long to the
Lesser Himalayas and lies in a tectonic fore deep. The Lesser Himalayas are comprised of fanglomerates followed by bedded quartzites, slates, phyllites and lowgrade schists. The rock types are ranging from green schist to lower amphibolite facies. The main rock types are schists, phyllites and quartzites.

Agriculture is the main occupation of the people. The agricultural activities are restricted to river terraces, gentle hill slopes and intermontane valleys. The major crops are rice, wheat, potato, pulses, millets and seasonal vegetables. Forest cover (58.38\%) is the main landuse. Alaknanda river, Ramganga River and their tributaries drain the district. Prominent of the tributaries are Dhauli ganga, Birhi ganga, Nandakini, Pindar etc. The main drainage patterns are dendritic, sub-dendritic, trellis, sub-rectangular and rectangular. The major rivers are Alaknanda, Dhauli ganga, Pindar are of antecedent type, where the drainage in the structurally disturbed area of subsequent type.

The climate varies from Sub-tropical monsoon type (mild winter, hot summer) to tropical upland type (mild winter, dry winter, short warm summer). The northern, northwestern, northeastern and western part of the district is perennially under snow cover, here the climate is sub-arctic type as the area is represented by lofty Himalayan Range. Severe winter and comparatively higher rainfall are the characteristic features of the northern part.

Larger part of the district is situated on the southern slopes of the outer Himalayas, monsoon currents can penetrate through trenched valleys, the rainfall reaches its maximal in the monsoon season that spans betweens June to September. Rainfall, spatially, is highly variable depending upon the altitude. In the Lesser Himalayan Zone (1000-3000 m) maximum rainfall occurs about 70 to $80 \%$ in southern half. August is the rainiest month. Rainfall rapidly decreases after September and it is the least in November. About 55 to 65\% rainfall occurs in the northern half in Central Himalayan Zone. About 17\% of the annual precipitation occurs in winter season.

Chamoli district comprises of high hills and mountains with very narrow valleys, deep gorges having very high gradient. The northern, northwestern, eastern and northeastern part of the district comprises Tethyan Himalaya with snow covered throughout the year. Physiographically the catchment of Alaknanda River comes under Gangotri-Badrinath-Kedarnath Complex (i.e. Himadri, Greater Himalaya zone) shows Radial Drainage pattern.

The soils are natural, dynamic, heterogeneous, nonrenewable resource, which support plant and animal life. The tract of Chamoli district consists of outward successsion of ridges viz; Greater Himalaya and Lesser Himalaya of decreasing height. These hills posse very little level land. The soils have developed from rocks like granite, schist, gneiss, phyllites, shales, slate etc. under cool and moist climate. Very steep to steep hills and Glacio-fluvial 


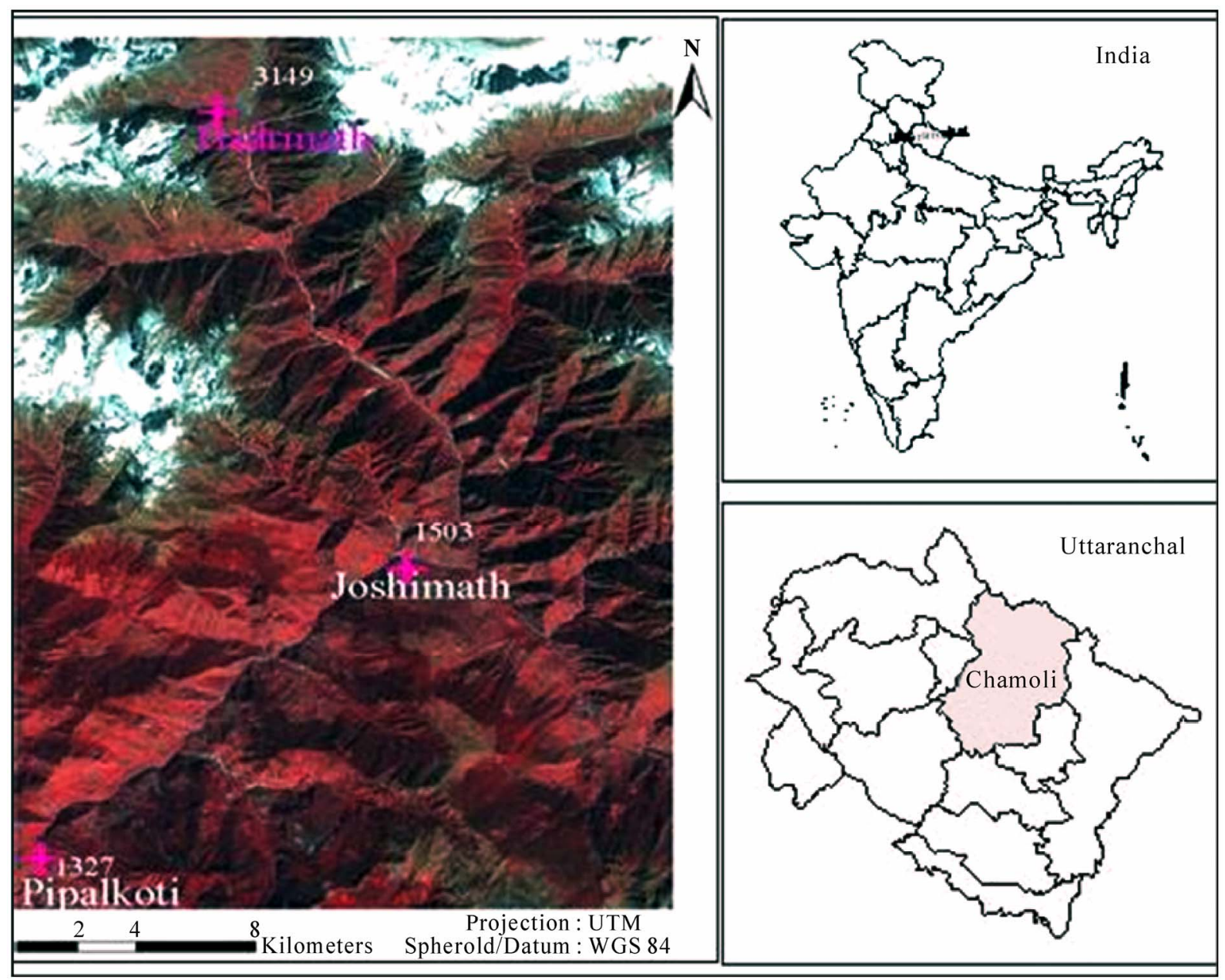

Figure 1. Satellite image showing study area.

valleys are dominantly occupied with very shallow to moderately shallow excessively drained, sandy-skeletal to loamy-skeletal, neutral to slightly acidic with low available water capacity soils. They have been classified as Lithic/Typic Cryorthents. These soils are in general under sparse vegetation. The Lesser Himalayan range is mainly composed of highly compressed and altered rocks like granite, phyllites, quartzite etc. and a major part of it is under forest. Intermittent sparse patchy terraced cultivation is also practiced on fairly steep hill slopes whereas dry and wet cultivation are prevalent on the uplands and low-lying valleys respectively. The broader valley slopes dominantly have deep, well drained, fine-loamy, moderately acidic and slightly stony.

\section{Data Used}

For Digital Elevation Model and ortho image generation from Cartosat-1 satellite data following data sets were used. The details of the Cartosat- 1 data are given in Table 1.

\section{Data Processing and Methodology}

A standard methodology has been adopted for the generation of DEM and ortho Image as is shown in Figure 2. It comprises of reconnaissance survey and DGPS survey, establishment of reference station by network adjustment with IGS stations, establishment of a sub reference station with respect to reference station, establishment of GCPs with respect to sub-reference station, stereo data analysis using RPCs and updation of RPCs using GCPs, generation of DEM and Ortho image generation from DEM, accuracy assessment of DEM and ortho image, generation of DEM by refining Rational Polynomial Coefficients (RPCs) with different number and distribution of GCPs, validating the DEM, generating the DEM, Ortho images at the best check point RMSE.

The field data of base and rover stations were processed in DGPS mode using Leica's Ski-Pro. The field recordings were first transferred to the system and the points were assigned as reference and rover accordingly. Single point processing (SPP) was first done for the base points and 
Table 1. Details of cartosat stereo pair used for DEM generation and orthorectification.

\begin{tabular}{cll}
\hline S. No. & \multicolumn{1}{c}{ Aft Scenes } & \multicolumn{1}{c}{ Fore Scenes } \\
\hline 1. & Satellite ID = CARTOSAT-1 & Satellite ID = CARTOSAT-1 \\
2. & Date of Pass $=09$ NOV2005 & Date of Pass $=09$ NOV2005 \\
3. & Sensor $=$ PAN_AFT & Sensor $=$ PAN_FORE \\
4. & Path $=0534$ & Path $=0534$ \\
5. & Row $=0258$ & Row $=0258$ \\
6. & Resolution along $=2.5 \mathrm{~m}$ & Resolution along $=2.5 \mathrm{~m}$ \\
7. & Resolution across $=2.5 \mathrm{~m}$ & Resolution across $=2.5 \mathrm{~m}$ \\
8. & No. of scans $=12000$ & No. of scans $=12000$ \\
9. & No. of Pixels $=12000$ & No. of Pixels $=12000$ \\
\hline
\end{tabular}

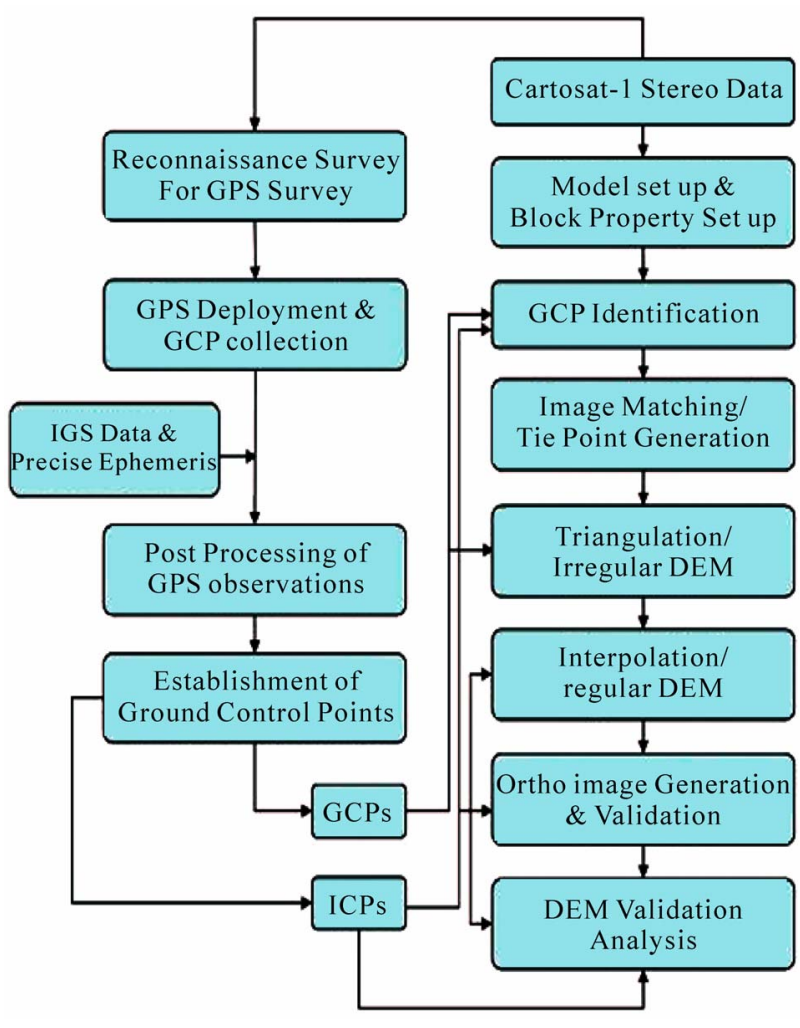

Figure 2. Flow chart methodology showing the detail procedure for DEM generation from Cartosat-1 stereo pair and orthorectification.

then the rover points were processed with respect to the base. The points which could not be accurately resolved were post-processed to remove ambiguities. However, only seventeen points could be determined precisely.

The fore and aft scenes of Cartosat-1 data were used to generate the Digital Elevation Model in Leica's Photogrammetry Suite with OrthoBase Pro. The scenes were provided with Rational Functions Coefficients (RPC). These coefficients are used to specify the geometric model, which defines the internal characteristics (i.e. internal geometry of the camera or sensor while capturing the imagery) and external parameters (i.e. original position and orientation of the camera or sensor).

The reference coordinate system is assigned a projection in UTM with spheroid and datum as WGS84. A block file is created in LPS and the two scenes added to the frame (Figure 3). The chipping coefficients are directly taken from the RPC text files provided with Cartosat-1 data.

Pyramid layers, based on a binomial interpolation algorithm and a Gaussian filter, were generated to preserve image contents and save computation time. Internal orientation is done to define the pixel coordinate positions of the calibrated fiducial marks within each image of the block. External orientation is done to define the position and orientation of the perspective centre. If very precise values (i.e. less than a meter) of exterior orientation are imported, the aerial triangulation process can even assigned a horizontal control as they were located beside cliff.

\section{Results and Discussions}

It was observed that while using only RPC information for Cartosat-1 stereo data, the error in height was in the range 124 to $286 \mathrm{~m}$. However, after use of GPS points and triangulation adjustment, the Cartosat DEM (Figure 4) becomes smooth and the error in height was reduced to 3 to $18 \mathrm{~m}$ (Figure 5). It was found that accuracy of contours generated from Cartosat- 1 stereo data was very accurate and close to ground height. Accuracy of DEM and ortho image was improved by triangulation iteration convergence option with less RMSE as shown in Table 2. The ortho image of Cartosat aft and fore image by DEM is shown in Figure 6. This Cartosat-1 stereo data can be used for height information generation at $4 \mathrm{~m}$ contour interval. The DEM generated from Cartosat-1 stereo data will be very much useful for topographic analysis in the field of water recourses, Landslide study, agriculture etc. 


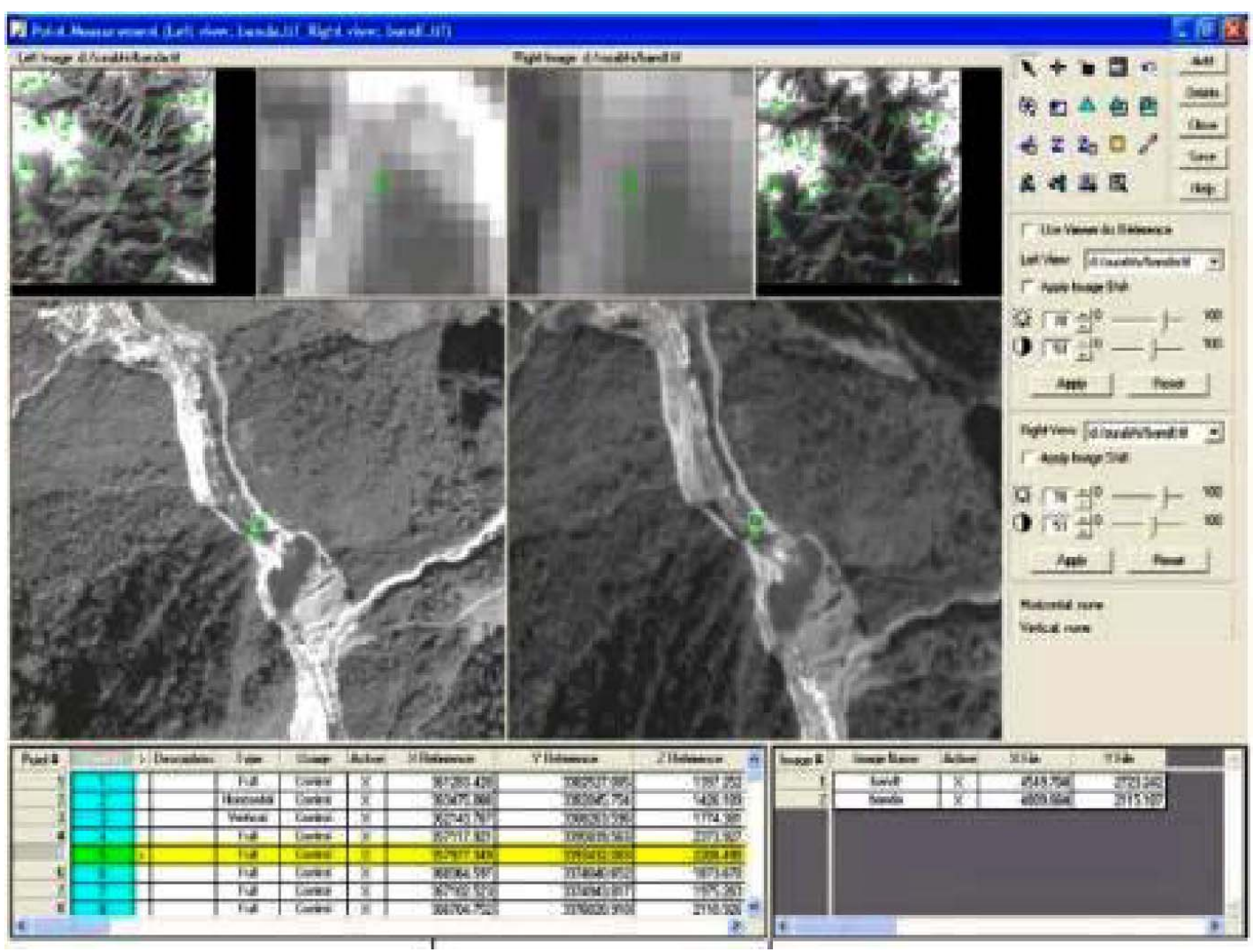

Figure 3. Generation of DEM and Ortho image generation in LPS.

Table 2. Details of triangulation summary showing RMSE error.

\begin{tabular}{|c|c|c|c|c|}
\hline \multicolumn{5}{|c|}{ Triangulation Summary } \\
\hline \multicolumn{5}{|c|}{ Triangulation Iteration Convergence: Yes } \\
\hline \multicolumn{3}{|c|}{ Total Image Unit-Weight RMSE: } & 0.2721570 & \\
\hline \multicolumn{2}{|c|}{ Control Point RMSE } & \multicolumn{3}{|c|}{ Check Point RMSE } \\
\hline Ground X & $0.0711773(10)$ & Ground X & & $7.4913788(3)$ \\
\hline Ground Y & $0.3628044(10)$ & Ground Y & & $7.3844452(3)$ \\
\hline Ground Z & $0.0930104(10)$ & Ground Z & & $6.8060341(3)$ \\
\hline Image $\mathrm{X}$ & $4.6107092(20)$ & Image $\mathrm{X}$ & & $0.4999596(3)$ \\
\hline Image $\mathrm{Y}$ & $8.0061207(20)$ & Image & & 2.8900647 (3) \\
\hline
\end{tabular}

The use of coarse resolution multispectral data of LISS-III $(23.5 \mathrm{~m})$ in the hilly terrain may not give accurate estimate of bio resource assessment due to high relief displacement. Therefore, the integration of the coarse resolution satellite data that of high-resolution satellite data (Cartosat PAN) after orthorectified helped in improving the accuracy of bio-resource assessment (Figure 7). The quality of orthorectification depends upon the quality of DEM. Therefore, high-resolution DEM needs to be used wherever possible. It is suggested that the loss of information in stretched areas could be supplemented with ground truth.

Digital Elevation Model generated from Cartosat-1 Stereo data could be improved with using more accurate and well-distributed GCP's for refining the rational function coefficients. Millimeter accuracy GCP's can be collected while using Geodetic Dual Frequency GPS in relative mode, which can improve accuracy of stereo model. It had also been observed that there was hardly any effect of small cloud covers present on the images, 


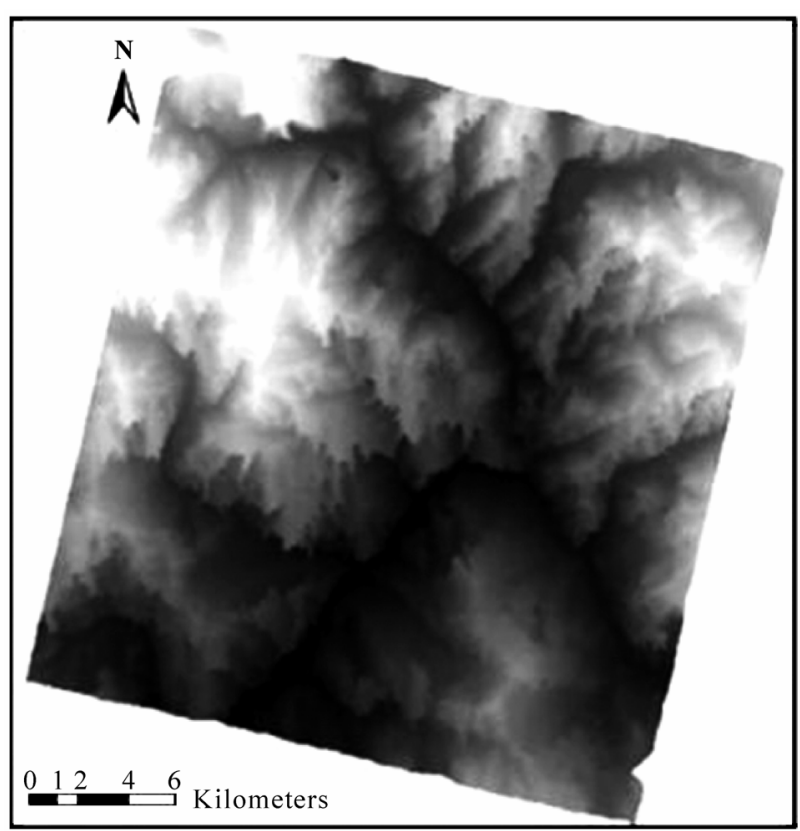

Figure 4. Digital elevation model generated from Cartosat1 satellite stereo pair.

during automatic conjugate point matching. Generally speaking, we can affirm that the Cartosat-1 DSM's accuracy decreases as the number of GCPs used decreases, with in- creasing ground sampling distance and with increasing terrain slope. Moreover, the use of high quality GCPs is fundamental to obtain good DSMs, filtering may help to enhance the elevation accuracy and the generation method used is fundamental for determining the final quality of products.

\section{Conclusions}

The reason for the accuracy difference obtained using only one against four (or more) GCPs is due to the use of RPCs for image orientation. Data processed without any GCPs mainly show linear systematic errors and few GCPs can be used to improve the positioning accuracy by fitting the RFM calculated coordinates to the coordi- nates of the additional GCPs; with one GCP is possible only to correct for shifts while using more GCPs an addi- tional transformation in the image space can be applied.

More in general, Cartosat- 1 stereo images have proven to be an excellent source of data for the production of DSMs with a ground resolution of about $10 \mathrm{~m}$. Even if within the range of available high resolution optical remote sensing satellites there are several units with a higher geometric resolution than Cartosat-1, Cartosat-1 DSMs can nevertheless be compared to similar models produced from higher resolution input imagery.

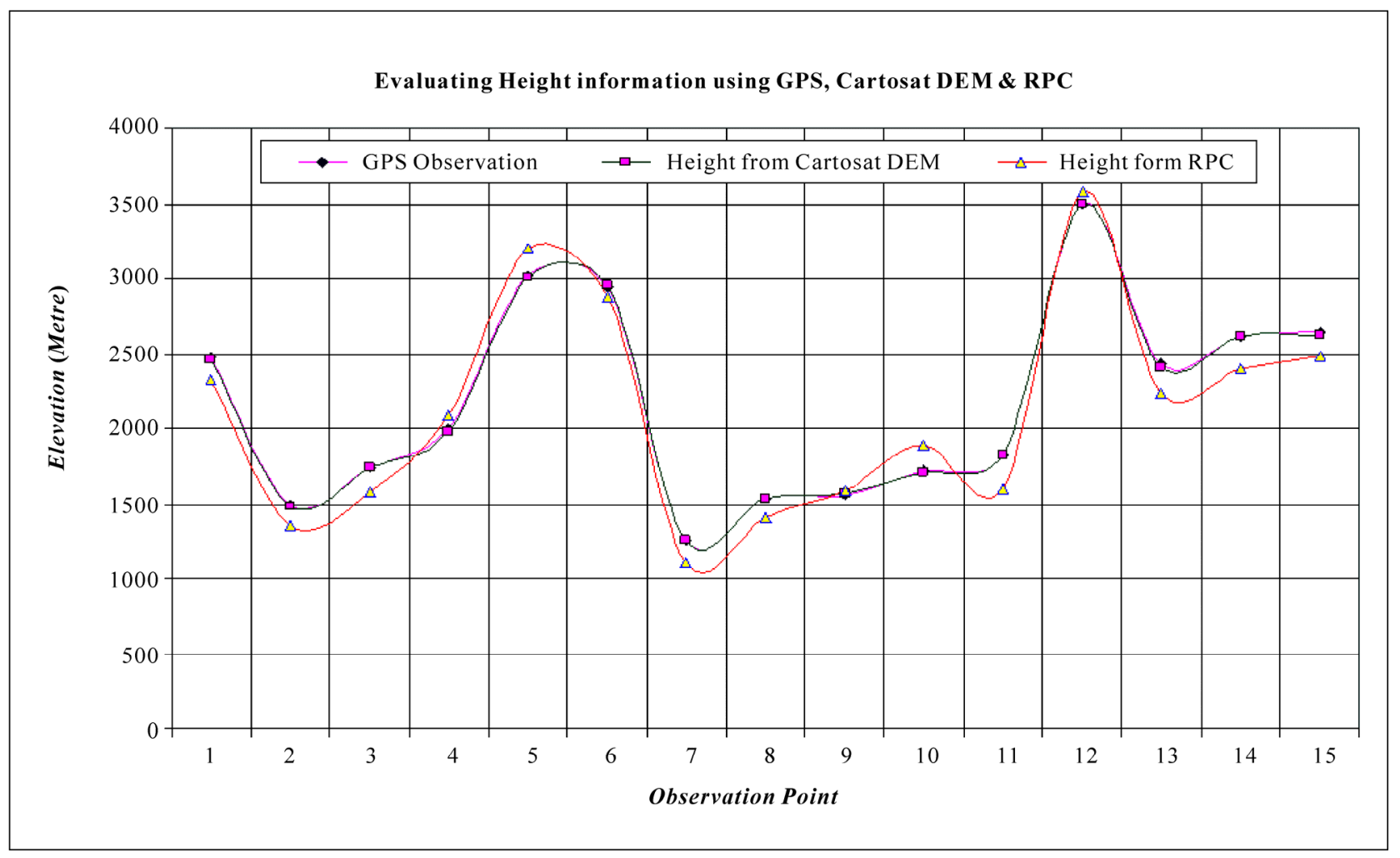

Figure 5. Graph showing comparison in height from GPS, Cartosat-1 derived DEM using GPS observation and Cartosat-1 derived DEM using RPC. 

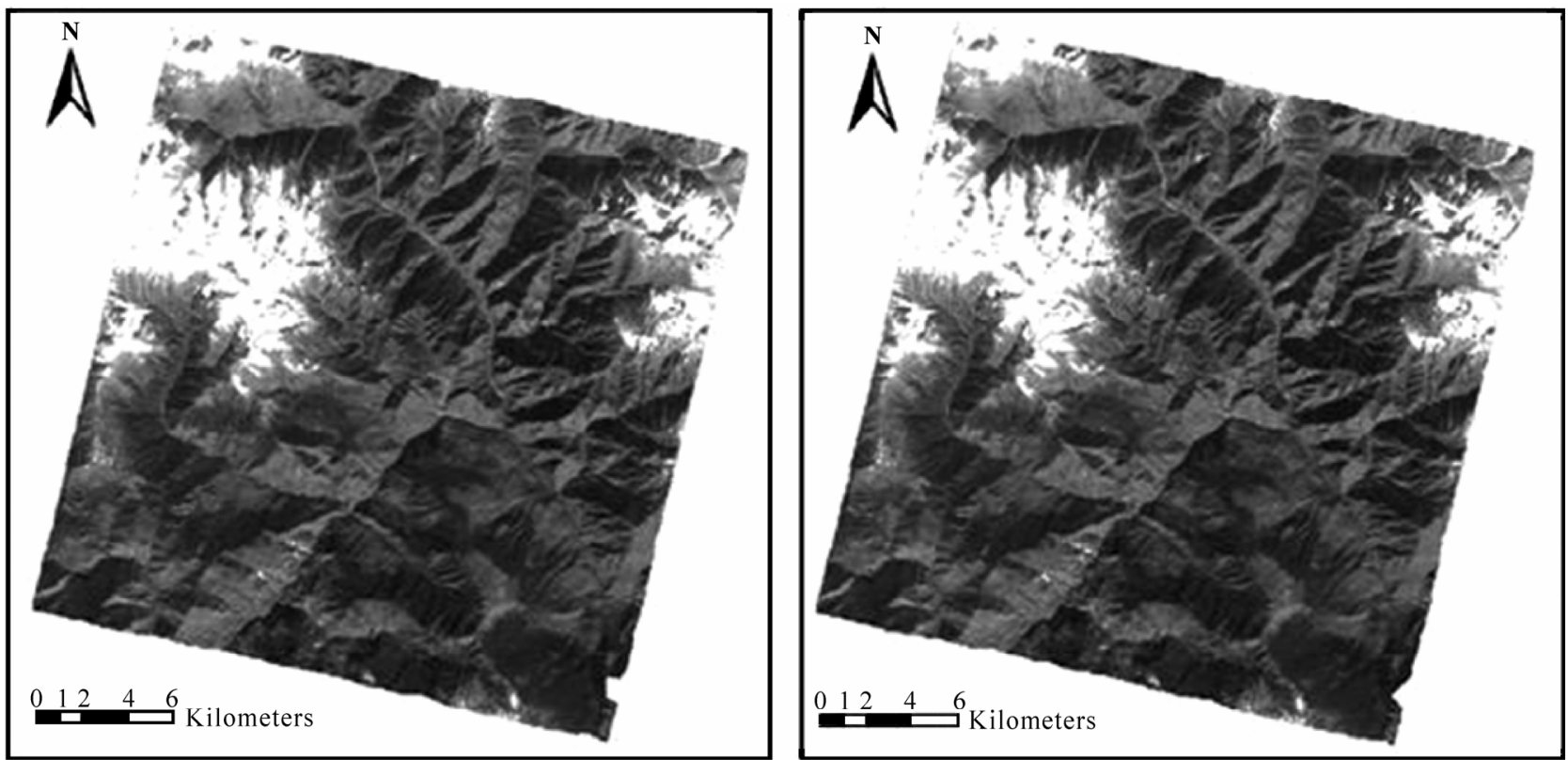

Figure 6. Ortho image generated (Fore \& Aft) from Cartosat-1 satellite Stereo pair.

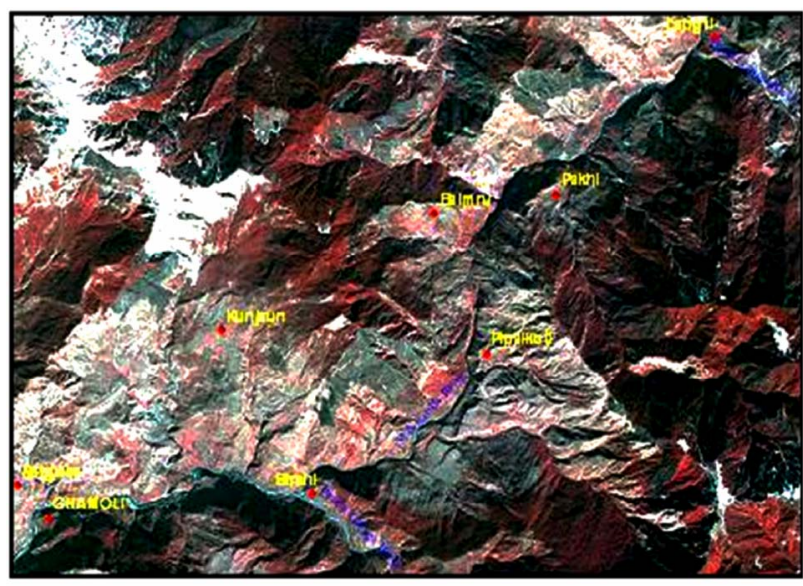

Liss-III + Pan Merged Satellite Image [IRS-1D]

Figure 7. Liss-III + pan merged orthorectifed data showing sharp ridge and valley profiles.

\section{Acknowledgements}

Authors thankfully acknowledge the constant encouragement and support received from Mrs. Shefali Aggarwal, Head PRSD, IIRS \& Prof. R. C. Lakhera, Head Geosciences Division, IIRS. Thanks are also due to Dr. R. D. Garg, Department of Civil Engineering, IIT Roorkee for his valuable suggestion and guidance.

\section{References}

[1] P. K. Srivastava, K. Gopala, B. Srinivasan, T. P. Amitabh, S. Trivedi and R. Nandakumar, "Cartosat-1 Data Prod- ucts for Topographic Mapping,” ISPRS Commission-IV International Symposium on Geospatial Databases for Sustainable Development, Vol. 37, 2006, pp. 1357-1362.

[2] R. Nandakumar, T. P. Srinivasan, K. B. Gopala and P. K. Srivastava, "Data Products for Cartosat-1," ISG Newsletter, Vol. 11, No. 2-3, 2005, pp. 18-24.

[3] C. V. Tao and Y. Hu, "A Comprehensive Study of the Rational Function Model for Photogrammetric Processing,” Photogrammetric Engineering \& Remote Sensing, Vol. 67, No. 12, 2001, pp. 1347-1357.

[4] K. Di, R. Ma and R. Li, "Rational Functions and Potential for Rigorous Sensor Model Recovery,” Photogrammetric Engineering \& Remote Sensing, Vol. 69, No. 1, 2003, pp. 33-41.

[5] J. Poon, C. S. Fracer and C. Zhang, "Digital Surface Models from High Resolution Satellite Imagery," Photogrammetric Engineering \& Remote Sensing, Vol. 73, No. 11, 2007, pp. 1225-1232.

[6] A. Nadeem, M. Anjum, A. Ritesh, P. Jayaprasad, S. K. Pathan, Ajai, D. K. Singh and A. K. Singh, "Extraction and Validation of Cartosat-1 DEM," Journal of the Indian Society of Remote Sensing, Vol. 35, No. 2, 2007, pp. 121-127.

[7] M. Crespi, F. Barbato, L. D. Vendictis, R. Onori, D. Polic, F. Volpe and X. Wang, "Orientation, Ortho-Rectification, DSM Extraction and 3D City Modeling by Cartosat-1 Stereo Imagery: First Results of a Test over Rome,” The International Archives of the Photogrammetry, Remote Sensing and Spatial Information Sciences, Goa, Vol. 36, 2006, pp. 1020-1025.

[8] C. S. Fracer and H. B. Hanley, "Bias Compensated RPCs for Sensor Orientation of High Resolution Satellite Imagery,” Photogrammetric Engineering \& Remote Sensing, Vol. 71, No. 8, 2005, pp. 909-915. 
[9] L. C. Chen, T. A. Teo and C. L. Liu, "The Geometrical Comparison of RSM and RFM for FORMOSAT-2 Satellite Images," Photogrammetric Engineering \& Remote Sensing, Vol. 72, No. 7, 2006, pp. 573-579.

[10] R. Dabrowski, M. Kedzierski, W. Fedorowicz, R. Kaczynski and J. Zych, "Geo-Interpretation Capabilities and Precision of an Ortho-Photomap Obtained from Cartosat Images," The International Archives of the Photogrammetry, Remote Sensing and Spatial Information Sciences, Vol. 36, 2006, pp. 1038-1040.
[11] P. Michalis and I. Dowman, "Sensor Model Evaluation and DEM Generation for Cartosat-1," The International Archives of the Photogrammetry, Remote Sensing and Spatial Information Sciences, Goa, Vol. 36, Part IVB, 2006, pp. 1009-1013.

[12] B. S. Rao, A. S. R. K. V. Murali Mohan, K. Kalyanaraman and K. Radhakrishnan, "Evaluation of Cartosat-1 Stereo Data of Rome," The International Archives of the Photogrammetry, Remote Sensing and Spatial Information Sciences, Goa, Vol. 36, Part 4B, 2006, pp. 1026-1029. 